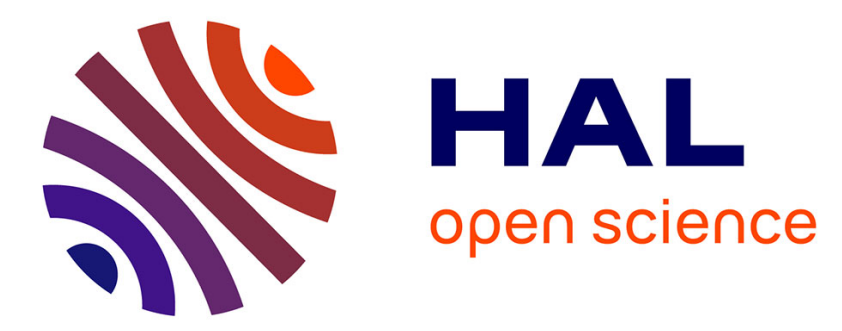

\title{
Avoiding disease mongering: A checklist for vascular physicians and researchers
}

\author{
Paul Frappé, Dagmar M. Haller, Andrea Roméas, Laurent Bertoletti, \\ Mathilde François, Helia Robert-Ebadi, Marc Righini
}

\section{To cite this version:}

Paul Frappé, Dagmar M. Haller, Andrea Roméas, Laurent Bertoletti, Mathilde François, et al.. Avoiding disease mongering: A checklist for vascular physicians and researchers. Thrombosis Research, 2019, 181, pp.120 - 123. 10.1016/j.thromres.2019.08.001 . hal-03487707

\section{HAL Id: hal-03487707 https://hal.science/hal-03487707}

Submitted on 20 Dec 2021

HAL is a multi-disciplinary open access archive for the deposit and dissemination of scientific research documents, whether they are published or not. The documents may come from teaching and research institutions in France or abroad, or from public or private research centers.
L'archive ouverte pluridisciplinaire $\mathbf{H A L}$, est destinée au dépôt et à la diffusion de documents scientifiques de niveau recherche, publiés ou non, émanant des établissements d'enseignement et de recherche français ou étrangers, des laboratoires publics ou privés.

\section{(ㄷ)(1) $\$$}

Distributed under a Creative Commons Attribution - NonCommerciall 4.0 International 


\section{Avoiding disease mongering: a checklist for vascular physicians and researchers}

Paul Frappéa,b,c,*, Dagmar M. Haller ${ }^{\mathrm{c}}$, Andrea Roméas ${ }^{\mathrm{a}}$, Laurent Bertoletti ${ }^{\mathrm{b}, \mathrm{d}}$, Mathilde François $^{\mathrm{e}, \mathrm{f}}$, Helia Robert-Ebadi ${ }^{\mathrm{g}}$, Marc Righini ${ }^{\mathrm{g}}$

\section{Authors' affiliations:}

${ }^{a}$ Department of General Practice, University of Saint-Etienne, Saint-Etienne, France

${ }^{\mathrm{b}}$ INSERM U 1059 Sainbiose DVH and INSERM CIC-EC 1408, University of Saint-Etienne, Saint-Etienne, France

${ }^{\mathrm{c}}$ Primary Care Unit, University of Geneva, Geneva, Switzerland

${ }^{\mathrm{d}}$ Department of Vascular Medicine and Therapeutics, University Hospital of Saint-Etienne, Saint-Etienne, France

${ }^{\mathrm{e}}$ Department of General Practice, University of Versailles-Saint-Quentin, Versailles, France ${ }^{\mathrm{f}}$ INSERM, Center for research in Epidemiology and Population Health, Université ParisSaclay, Université Paris-Sud, UVSQ, Villejuif, France

$g$ Division of Angiology and Hemostasis, Geneva University Hospitals and Faculty of Medicine, Geneva, Switzerland

\section{*Corresponding author:}

Dr. Paul Frappé

Department of General Practice, Faculty of Medicine, University of Saint-Etienne, 10 rue de la Marandière, 42270 Saint-Priest-en-Jarez, France

Phone: +33 4774214 16; Fax: +33 4774214 29; email: paul.frappe@univ-st-etienne.fr

Funding: No funding

Conflicts of interest: The authors declare no competing interests.

Word count: 1820 words

Keywords: Medical ethics, Awareness, Disease management, Venous thromboembolism, Saphenous vein 


\begin{abstract}
Disease mongering is an expression created in 1992 by a medical journalist, Lynn Payer, to qualify the "selling of sickness that widens the boundaries of treatable illness in order to expand markets for those who sell and deliver treatments". This interesting concept led us to question whether, as researchers with publication and career interests in superficial vein thrombosis, we were not shaping a benign condition into a disease.

Since the publication of the CALISTO trial in 2010, anticoagulant management of superficial vein thrombosis remains debated. Issues raised, such as the cost-effectiveness of the treatment strategy, the use of a composite endpoint including death, the low event rate without mortality reduction and conflict of interest due to industrial funding.

We searched Embase, Medline, Web of science, and Opengrey databases to review all aspects about disease mongering raised in the literature and created a checklist with seventeen items. We used this checklist as support for a narrative review, questioning known literature on superficial vein thrombosis.

The main issues pointing towards disease mongering concerned definition and promotion; whereas management seemed rather spared. Many arguments could be counterbalanced, but researchers should pay particular attention to three major points: exaggeration of the severity of the disease and potential adverse outcomes without treatment, promotion by opinion leaders, and an openly declared, yet undoubtedly present, conflict of interest situation.
\end{abstract}




\section{Introduction}

Over the last decade, studies have deeply changed the perception of the severity of superficial vein thrombosis (SVT) and its management. The publication of the CALISTO trial in 2010 triggered numerous reactions.[1] This trial was the first to demonstrate the efficacy and safety of fondaparinux therapy for superficial vein thrombosis. The study was praised for being carefully conducted.[2,3] Yet, the accompanying editorial and letters raised issues, including the diversity of clinical presentations,[4,5] the need to restrict treatment to those at higher risk,[2,6] the unknown optimal duration of treatment,[5] among others.[2,4-8]

Taken as a whole, these issues draw attention to the risk of "disease mongering", an expression, created in 1992 by a medical journalist, Lynn Payer, for the "selling of sickness that widens the boundaries of treatable illness in order to expand markets for those who sell and deliver treatments".[9] In addition to its unethical aspects, disease mongering leads to unnecessary treatments and potential side effects and costs. It builds on unclear boundaries between health and illness, which are influenced by a wide array of beliefs about the causes of disease and modifies individual and social perceptions of health and illness.[10,11]

The pharmaceutical industry is the main actor accused of disease mongering. However, researchers also constitute an exposed population. Whether consciously or not, publication and career considerations can lead authors to exaggerate the importance of their research. As authors of several papers on SVT, this led us to question whether we were not shaping a rather benign condition into an illness.

To address this question we created a checklist summarizing all the attributes of disease mongering raised in the literature. We applied it to analyze the extent to which SVT could be subject to disease mongering.

\section{Identifying disease mongering}

We searched for the term "disease mongering" in Embase, Medline, Web of science, and Opengrey databases, in all indexing fields, with no date restrictions. A secondary search was carried out based on the references cited in the collected documents. The inclusion criteria were original articles, comments, editorials, letters to the editor and books, written in English or French, and dealing with disease mongering at least in part. The selection of the documents was carried out by two researchers (AR and PF). We included 87 documents, with publication dates ranging from 1992 to 2019 (Fig. 1.). Most of them were opinion pieces and 49 (56.3\%) were single-authored documents. 
Thirty "medical" conditions were cited. These were a mixture of risk factors, symptoms, clinical signs and diseases, including some physiological conditions such as baldness or menopause. Considering risk factors such as hypercholesterolemia or hypertension - if they can be considered as real diseases requiring medication (i.e., "primary prevention of cardiovascular disease") - the lowering of thresholds between normality and disease leads to a considerable increase in the number of individuals considered sick.[12]

Our analysis provided a list of seventeen arguments, in relation to the definition of conditions, their management and their promotion (Table 1). These helped us structure our thoughts about SVT, as illustrated in the Table and detailed below.

\section{Yes, SVT is disease mongering}

\section{Definition}

SVT is a benign condition, occurring most often in varicose veins due to blood stasis in these distended low flow vessels. When isolated, i.e., without concomitant deep vein thrombosis (DVT) or pulmonary embolism (PE), which is the case in the vast majority of patients, the clinical outcome is usually favorable: pain is reduced by more than half over the first week, and inflammation regresses in 2 to 3 weeks.[13-16]

CALISTO results cannot apply to every patient with SVT.[1] Many patients were excluded from the trial due to restrictive eligibility criteria excluding patients with SVT measuring less than $5 \mathrm{~cm}$ in length and patients with a high thromboembolic risk (active cancer, recent history of thromboembolism, SVT located at less than $3 \mathrm{~cm}$ of the sapheno-femoral junction $(\mathrm{SFJ}))$ or high hemorrhagic risk and severe renal failure.[4,7]

SVT is no more than a risk factor for venous thromboembolism. It is not a disease in itself. The aim of treating SVT is to reduce the thromboembolic risk at 3 months, not to act on the signs and symptoms of SVT. The question is not to know if SVT needs to be treated, but if a prophylactic dose anticoagulant treatment is justified when a patient has a previous history of SVT and risk factors.[17,18]

The definition of SVT can be questioned, as the diagnostic accuracy of lower limb venous compression ultrasonography is limited, and results are subject to interobserver variability. Moreover, differentiating acute SVT from sequelae from a previous SVT on ultrasonography can be highly challenging.

Several areas remain uncertain. The pathophysiological mechanisms of extension of SVT to DVT are poorly known. Two main hypotheses are suggested: (i) migration of the SVT toward the deep venous system via the SFJ, the sapheno-popliteal junction or a perforating vein; and 
(ii) a state of hypercoagulability resulting in clots both in the superficial and deep venous systems.[19]

\section{Management}

We did not find any argument in favor of disease mongering regarding SVT management.

\section{Promotion}

In terms of conflicts of interest, the CALISTO trial was funded by GlaxoSmithKline, manufacturer of fondaparinux. This company obviously gains a large market by promoting a 45-day anticoagulant treatment for SVT.[2]

The CALISTO trial did not find any difference in bleeding risk, whereas anticoagulation is an inherent risk factor for bleeding. Is it too beautiful to be real? The literature has previously highlighted the techniques commonly used by pharmaceutical companies to obtain the results they want from clinical trials. These include undertaking multicenter trials and selecting for publication results from centers that are favorable or conducting subgroup analyses and selecting the most favorable ones for publication.[20]

As it reported a benefit without incremental risk, CALISTO opened the doors widely to the delivery of awareness messages about the severity of SVT. Fondaparinux has been the only treatment which has been validated through a randomized trial.[21] As a result, promoting SVT as a serious disease that needs treatment automatically promotes fondaparinux.

Highlighting severe (yet extremely rare) complications of isolated SVT, such as PE and death, may favor the wish to treat.[8] Long term complications of isolated SVT are rare (less than $3 \%$ at 3 months) and most often comprised of extensions or recurrences of SVT. Yet these complications justify the anticoagulant treatment assessed in CALISTO.

Moreover, beautiful figures are available to portray the fondaparinux effect: doctors will definitely be convinced by a relative risk reduction (RRR) of $85 \%$, even if it masks an absolute risk reduction of DVT or PE of only $1 \%$, and a number needed to treat of 100 to prevent one DVT or PE.[2] All this composes an ideal message for opinion leaders to raise awareness on SVT.

\section{No, SVT is not disease mongering}

\section{Definition}

SVT is a pathological entity. Its symptoms, such as pain, redness, warmth, swelling and tenderness lead patients to consult their physician.[14,22,23] The SVTs studied in the literature have been symptomatic and not the result of any screening process.[19] The acute episodic character of SVTs distinguishes them from simple variations within the norm.[13,14] 
There will be no global expansion of SVT treatment. There is no evidence to recommend anticoagulation for SVT measuring less than $5 \mathrm{~cm}$.[24-26]

As a risk factor, there is no specific management for patients with a history of SVT, except the additional argument for treating underlying varicose veins when appropriate.[19]

The definition of SVT is clear. When SVT is suspected by clinical symptoms, its diagnosis needs objective confirmation by lower limb venous compression ultrasonography. We did not find data on the diagnostic performance of compression ultrasonography for SVT. For the diagnosis of DVT, compression ultrasonography has a sensitivity of $91 \%$ and a specificity of $99 \%$, with an interoperators kappa of 1.0.[27]

Pathophysiology of SVT is well known and summarized in the Virchow triad: hypercoagulability, blood stasis and venous wall damage. Anticoagulation responds directly to the thrombotic component of the disease.

\section{Management}

The current trend is rather to restrict indications to people with the same characteristics as participants of the CALISTO trial and to target a high risk population.[2,6,28]

Anticoagulation focuses SVT treatment on the etiological mechanism and on protection against thromboembolic complications rather than on symptomatic treatment, which is classically based on topical or oral NSAID. The aim of anticoagulant treatment is not primarily symptom relief, but the prevention of thromboembolic complications.[1,29]

To our knowledge, there are no self-diagnosis or screening campaigns for SVT.

\section{Promotion}

Regarding potential conflicts of interest, CALISTO was funded by industry because no other funding source exists today for such large scale trials on therapeutic agents. Government grants favor studies that are not of interest to industry. CALISTO followed good clinical practice guidelines, and its protocol was registered in Clinicaltrial.gov.[1]

Communication about SVT is not anarchic. Messages do not promote screening. They are focused on an initial risk of SVT, due to its association with a concomitant DVT or PE rather than on the rate of long term complications. The literature encourages physicians to systematically refer every patient with suspected SVT to perform an ultrasound, in order to confirm diagnosis and extension and exclude concomitant DVT.[30,31,24,25]

Communication about anticoagulation regimens only concerns physicians, aiming to limit unnecessary and potentially iatrogenic treatments that are currently prescribed, such as therapeutic anticoagulation.[32] To our knowledge, fondaparinux and low-molecular-weight heparin (LMWH) are not involved in direct to consumer advertising. Guidelines subsequently 
extended possible treatment to all LMWH, diluting the specific interests of the only company manufacturing fondaparinux.[25] As stated by the CALISTO authors, death was not included in the composite criterion in the initial protocol of the study. It was added secondarily following European Medicines Agency request, so as not to miss any fatal PE.[8] Fondaparinux significantly reduced, by the same magnitude $(85 \%)$, the risk of each thromboembolic component of the primary efficacy outcome, except death. CALISTO results were presented with both relative risk reduction (RRR) figures and absolute risk reduction figures and corresponding number needed to treat (NNT). The symptomatic venous thromboembolism rate of $1.3 \%$ in the CALISTO study is similar to the one supporting thromboprophylaxis in untreated medical and surgical inpatients.[2] Nevertheless, for those still suspicious, the difference between RRR and NNT gives you an easy tool to identify partisan speeches, which present only one of these two figures.

\section{Conclusions}

The checklist offers a useful support to guide our questioning about the potential for disease mongering when studying the field of SVT. The main elements pointing towards disease mongering are in relation to definition and promotion, whereas management seems rather spared. Many arguments can be counterbalanced, but researchers should pay particular attention to three major points: exaggeration of the severity of disease and outcomes prevented by the treatment, promotion by opinion leaders, and an openly declared, yet undoubtedly present conflict of interest. As a consequence, we advise clinicians to favor shared decision making and to respect CALISTO's treatment criteria in their management of patients with SVT. 


\section{References}

[1] H. Decousus, P. Prandoni, P. Mismetti, R.M. Bauersachs, Z. Boda, B. Brenner, S. Laporte, L. Matyas, S. Middeldorp, G. Sokurenko, Fondaparinux for the treatment of superficial-vein thrombosis in the legs, N. Engl. J. Med. 363 (2010) 1222-1232.

[2] L. Goldman, J. Ginsberg, Superficial phlebitis and phase 3.5 trials, N. Engl. J. Med. 363 (2010) 1278-1280. doi:10.1056/NEJMe1005749.

[3] A. King, Thrombosis: An effective therapy for leg SVT, Nat. Rev. Cardiol. 7 (2010) 667. doi:10.1038/nrcardio.2010.177.

[4] S. Bozzato, E. Rancan, W. Ageno, Fondaparinux for the treatment of superficial vein thrombosis in the legs: the CALISTO study, Expert Opin. Pharmacother. 12 (2011) 835837. doi:10.1517/14656566.2011.552430.

[5] W. Ageno, ACP Journal Club. Fondaparinux reduced a composite of VTE complications or death in superficial leg-vein thrombosis, Ann. Intern. Med. 154 (2011) JC2-3. doi:10.1059/0003-4819-154-4-201102150-02003.

[6] M. Blondon, M. Righini, H. Bounameaux, D.L. Veenstra, Fondaparinux for isolated superficial vein thrombosis of the legs: a cost-effectiveness analysis, Chest. 141 (2012) 321-329. doi:10.1378/chest.11-0625.

[7] A. Brodin-Sartorius, F. Martinez, C. Legendre, Treatment of superficial thrombophlebitis, N. Engl. J. Med. 364 (2011) 380; author reply 380-381; discussion 381. doi:10.1056/NEJMc1011872\#SA1.

[8] R. Loewenstein, Treatment of superficial thrombophlebitis, N. Engl. J. Med. 364 (2011) 380; author reply 380-381; discussion 381. doi:10.1056/NEJMc1011872\#SA2.

[9] L. Payer, Disease-Mongers: How Doctors, Drug Companies, and Insurers Are Making You Feel Sick, Reprint, John Wiley \& Sons, New York, 2011.

[10] R. Moynihan, A. Cassels, Selling Sickness: How the World's Biggest Pharmaceutical Companies Are Turning Us All Into Patients, 1 edition, Nation Books, New York, 2006.

[11] A. Kleinman, Concepts and a model for the comparison of medical systems as cultural systems, Soc. Sci. Med. 12 (1978) 85-95.

[12] H. Wolinsky, Disease mongering and drug marketing. Does the pharmaceutical industry manufacture diseases as well as drugs?, EMBO Rep. 6 (2005) 612-614. doi:10.1038/sj.embor.7400476.

[13] G. Górski, W. Noszczyk, W. Kostewicz, P. Szopiński, M. Kielar, J. Michalak, A. Marianowska, D. Wilkoswski, Progress of local symptoms of superficial vein thrombosis vs. duplex findings, VASA Z. Für Gefässkrankh. 33 (2004) 219-225. 
[14] A. Spirkoska, M.K. Jezovnik, P. Poredos, Time Course and the Recanalization Rate of Superficial Vein Thrombosis Treated With Low-Molecular-Weight Heparin, Angiology. (2014). doi:10.1177/0003319714533183.

[15] G. Belcaro, M.R. Cesarone, M. Dugall, B. Feragalli, E. Ippolito, M. Corsi, M. Hosoi, U. Cornelli, A. Ledda, G. Gizzi, R. Luzzi, M. Georgiev, Topical formulation of heparin is effective in reducing the symptoms of superficial venous thrombosis: a monocenter, observer-blind, placebo-controlled randomized study, Panminerva Med. 53 (2011) 3-11.

[16] E. Kalodiki, V. Stvrtinova, C. Allegra, G. Andreozzi, P.-L. Antignani, R. Avram, B. Brkljacic, F. Cadariou, C. Dzsinich, J. Fareed, L. Gaspar, G. Geroulakos, A. Jawien, M. Kozak, C.R. Lattimer, E. Minar, H. Partsch, F. Passariello, M. Patel, Z. Pécsvárady, P. Poredos, K. Roztocil, A. Scuderi, M. Sparovec, M. Szostek, M. Skorski, Superficial vein thrombosis: a consensus statement, Int. Angiol. J. Int. Union Angiol. 31 (2012) 203-216.

[17] R.E.J. Roach, W.M. Lijfering, A. van Hylckama Vlieg, F.M. Helmerhorst, F.R. Rosendaal, S.C. Cannegieter, The risk of venous thrombosis in individuals with a history of superficial vein thrombosis and acquired venous thrombotic risk factors, Blood. 122 (2013) 4264-4269. doi:10.1182/blood-2013-07-518159.

[18] S.M. Bates, Superficial venous thrombosis: recognizing the risk, Blood. 122 (2013) 4159-4160. doi:10.1182/blood-2013-11-537019.

[19] H. Décousus, L. Bertoletti, P. Frappé, Spontaneous acute superficial vein thrombosis of the legs: do we really need to treat?, J. Thromb. Haemost. JTH. 13 Suppl 1 (2015) S230237. doi:10.1111/jth.12925.

[20] H.C. Williams, L. Naldi, C. Paul, A. Vahlquist, S. Schroter, R. Jobling, Conflicts of interest in dermatology, Acta Derm. Venereol. $86 \quad$ (2006) 485-497. doi:10.2340/00015555-0191.

[21] L. Duffett, C. Kearon, M. Rodger, M. Carrier, Treatment of Superficial Vein Thrombosis: A Systematic Review and Meta-Analysis, Thromb. Haemost. (2019). doi:10.1055/s-0039-1677793.

[22] P. Prandoni, D. Tormene, R. Pesavento, High vs. low doses of low-molecular-weight heparin for the treatment of superficial vein thrombosis of the legs: a double-blind, randomized trial, J. Thromb. Haemost. JTH. 3 (2005) 1152-1157. doi:10.1111/j.15387836.2005.01391.x.

[23] P. Frappé, A. Buchmuller-Cordier, L. Bertoletti, C. Bonithon-Kopp, S. Couzan, P. Lafond, A. Leizorovicz, A. Merah, E. Presles, P. Preynat, B. Tardy, H. Décousus, STEPH Study Group, Annual diagnosis rate of superficial vein thrombosis of the lower 
limbs: the STEPH community-based study, J. Thromb. Haemost. JTH. 12 (2014) 831838. doi:10.1111/jth.12575.

[24] B. Cosmi, Management of superficial vein thrombosis, J. Thromb. Haemost. JTH. 13 (2015) 1175-83. doi:10.1111/jth.12986.

[25] C. Kearon, E.A. Akl, A.J. Comerota, P. Prandoni, H. Bounameaux, S.Z. Goldhaber, M.E. Nelson, P.S. Wells, M.K. Gould, F. Dentali, M. Crowther, S.R. Kahn, Antithrombotic therapy for VTE disease: Antithrombotic Therapy and Prevention of Thrombosis, 9th ed: American College of Chest Physicians Evidence-Based Clinical Practice Guidelines, Chest. 141 (2012) e419S-94S. doi:10.1378/chest.11-2301.

[26] G. Scott, A.J. Mahdi, R. Alikhan, Superficial vein thrombosis: a current approach to management, Br. J. Haematol. 168 (2015) 639-645. doi:10.1111/bjh.13255.

[27] A.W. Lensing, P. Prandoni, D. Brandjes, P.M. Huisman, M. Vigo, G. Tomasella, J. Krekt, J. Wouter Ten Cate, M.V. Huisman, H.R. Büller, Detection of deep-vein thrombosis by real-time B-mode ultrasonography, N. Engl. J. Med. 320 (1989) 342-345. doi:10.1056/NEJM198902093200602.

[28] J. Beyer-Westendorf, S.M. Schellong, H. Gerlach, E. Rabe, J.I. Weitz, K. Jersemann, K. Sahin, R. Bauersachs, SURPRISE investigators, Prevention of thromboembolic complications in patients with superficial-vein thrombosis given rivaroxaban or fondaparinux: the open-label, randomised, non-inferiority SURPRISE phase $3 \mathrm{~b}$ trial, Lancet Haematol. (2017). doi:10.1016/S2352-3026(17)30014-5.

[29] M. Righini, H. Robert-Ebadi, F. Glauser, M. Blondon, P. Ouvry, J.-M. Diamand, A. Tissot, P. Frappe, I. Quere, S.R. Kahn, J.-P. Galanaud, G. Le Gal, Effect of anticoagulant treatment on pain in distal deep vein thrombosis: an ancillary analysis from the cactus trial, J. Thromb. Haemost. JTH. 17 (2019) 507-510. doi:10.1111/jth.14387.

[30] M.G.R. De Maeseneer, Superficial thrombophlebitis of the lower limb: practical recommendations for diagnosis and treatment, Acta Chir. Belg. 105 (2005) 145-147.

[31] C. Tait, T. Baglin, H. Watson, M. Laffan, M. Makris, D. Perry, D. Keeling, British Committee for Standards in Haematology, Guidelines on the investigation and management of venous thrombosis at unusual sites, Br. J. Haematol. 159 (2012) 28-38. doi:10.1111/j.1365-2141.2012.09249.x.

[32] H. Decousus, P. Frappé, S. Accassat, L. Bertoletti, A. Buchmuller, B. Seffert, A. Merah, F. Becker, I. Queré, A. Leizorovicz, Epidemiology, diagnosis, treatment and 
management of superficial-vein thrombosis of the legs, Best Pract. Res. Clin. Haematol. 25 (2012) 275-284. doi:10.1016/j.beha.2012.07.005.

\section{Acknowledgements}

We thank Jennifer Hasselgard-Rowe, Alec Hester and Eva Franziska Pfarrwaller for their editorial advice.

\section{Contributors}

PF had the original idea for the paper and all authors developed the content. PF, AR and DME wrote the first draft of the paper, and LB, MF, HRE and MR adapted and revised this draft. $\mathrm{PF}$ is the guarantor. 
Fig. 1. Flow diagram for study inclusion and exclusion

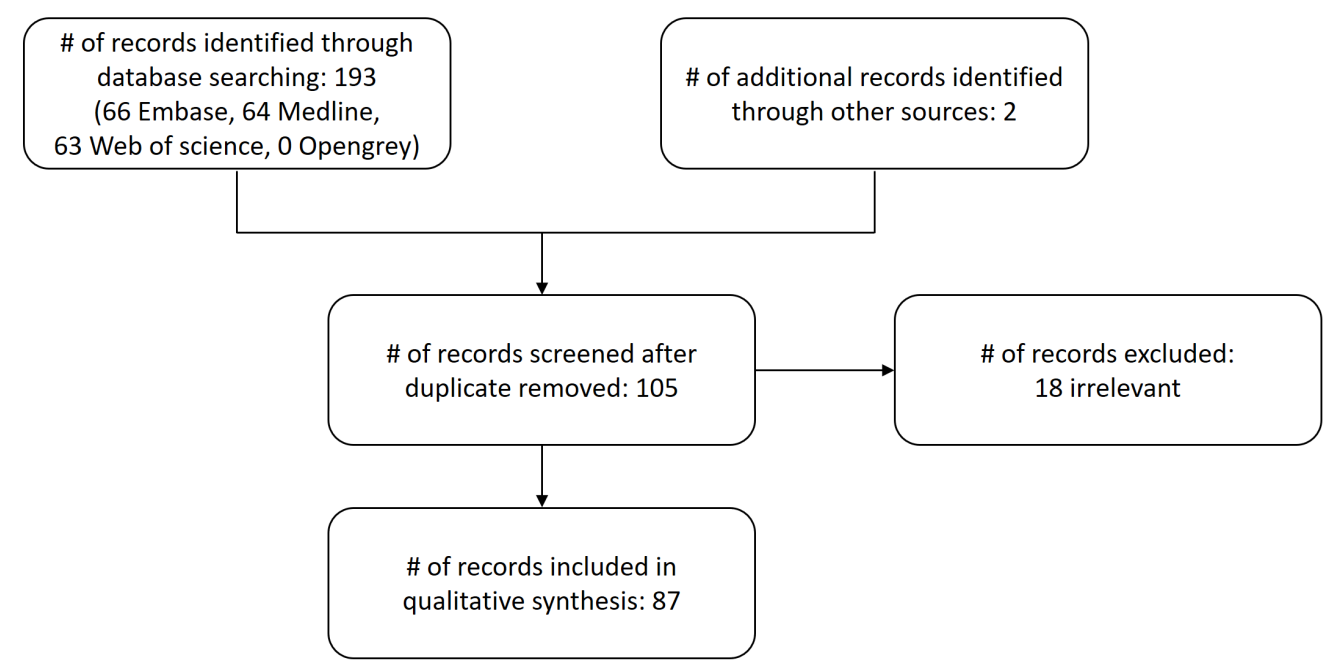


Table 1. Checklist of disease mongering arguments

Checklist

Definition

Condition which could be considered as normal

Increase in the prevalence of the condition

Risk factor considered as a disease

Approximate or controversial definition of the condition

Unknown pathophysiological mechanisms

Management

Extension of indications

Symptomatic rather than etiological treatment

Promotion of self-diagnosis

Promotion of "lifestyle drugs"

\section{Promotion}

Conflict of interest situation

Minimization of management side effects

Disease awareness campaigns

Direct to consumer advertising

Using fear as a lever

Exaggeration of management efficacy

Exaggeration of condition severity

Promotion or awareness by opinion leaders 